www.jmscr.igmpublication.org

Index Copernicus Value: 79.54

ISSN (e)-2347-176x ISSN (p) 2455-0450

crossref DOI: https://dx.doi.org/10.18535/jmscr/v7i6.62

\title{
Recurrent Pleomorphic Sarcoma of Scalp: A Case Report
}

\author{
Authors \\ Dr Amit Kichloo ${ }^{1}$, Dr Parag Roy ${ }^{2}$, Dr Sakina Mankada ${ }^{3}$, Dr U Suryanarayan ${ }^{4}$, \\ Dr Akash Pandya ${ }^{5}$ \\ 1,3,4 Resident Doctor Radiation Oncology GCRI \\ ${ }^{2}$ Assistant Professor Radiation Oncology GCRI \\ ${ }^{5}$ Professor and HOD Radiation Oncology GCRI
}

\section{Introduction}

The differential diagnosis of skull and scalp lesions is broad and includes congenital, inflammatory, traumatic and neoplastic lesions. Though there are few reports on pleomorphic sarcoma of scalp and approach to management, this case report is to draw attention for role of radiotherapy as adjuvant treatment modality for this disease.

\section{Case Report}

A 33 years old male presented in radiotherapy OPD at our institute with swelling over the right occipital region. On taking detailed history, patient mentioned that around one and half years back he had a painless scalp swelling on the right occipital region. He was operated at local hospital for the same.

In December 2016 patient again developed scalp lesion at the same site. CECT brain showed $3.3 \mathrm{x}$ $1.9 \mathrm{~cm}$ non enhancing well defined extracalvarial lesion in right occipital region with no intracranial extension or bone erosion (as shown in fig.1). Chest $\mathrm{X}$ ray was normal.
On local examination, $4 \times 3 \mathrm{~cm}$ size non tender swelling with no signs of inflammation over right occipital region. Physical examination was within normal limits and so were other hematological and biochemical parameters.

After multidisciplinary discussion, patient was operated for scalp lesion at same site in December 2016. Histopathology revealed atypical spindle cells with surgical margins free (as shown in fig.2). Immunohistochemistry revealed KI-67 index as $30 \%$, Desmin positive (+), CD 68 focally positive (+) and S 100, PAN CK negative (-) (as shown in table below) 


\section{Immunohistochemistry}

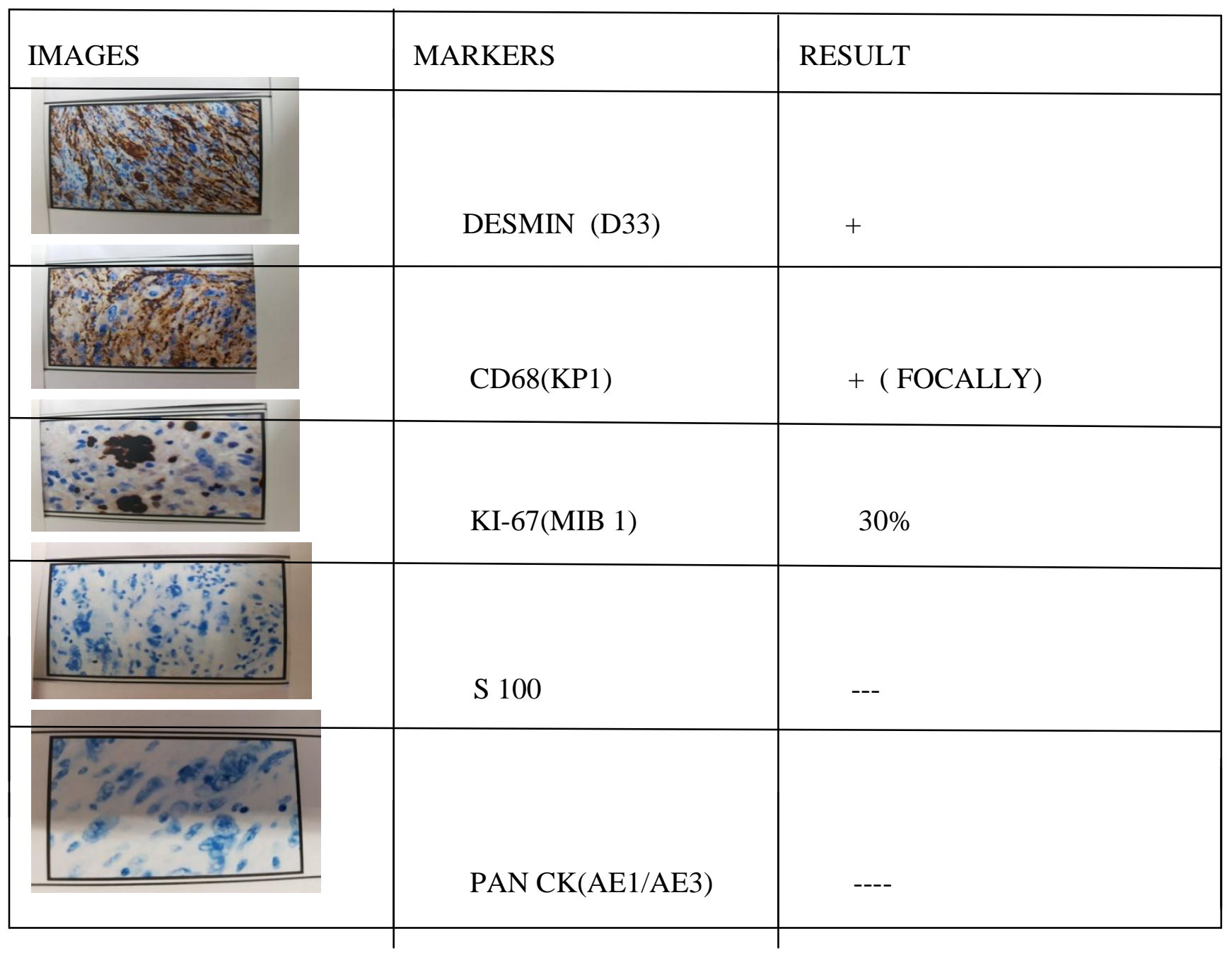

The patient was again referred to RT department. On examination healthy scar was noted at operated site. The patient was treated with external beam radiotherapy with $6 \mathrm{MeV}$ electron, $50 \mathrm{~Gy}$ in 20 fractions at $250 \mathrm{cGy}$ per fraction 5 days a week, in 4 weeks from 7/2/2017 to 2/3/2017 thereafter patient was kept on regular follow up.

\section{Result}

The patient is asymptomatic at present fig. $(3,4)$ and is on regular follow up.

\section{Discussion}

Malignant fibrous histiocytoma (MFH) a pleomorphic sarcoma of uncertain origin was first described by O'Brien and Stout in $1964^{(1)}$. It is the most common primary soft tissue sarcoma in adults. MFHs commonly arises in the extremities and the trunk, although it can occur anywhere because of its mesenchymal origin ${ }^{(5)}$. MFH of scalp is extremely rare; moreover, there is paucity of literature with regards to prevalence of scalp and skull neoplasms. The incidence of malignant neoplasms in the scalp ranges from 0 to $7.7 \%$, a great majority of them are in fact believed to be metastatic rather than primary neoplasms ${ }^{(2,3)}$. The presenting symptoms of the various scalp and skull lesions are quite similar, regardless of the primary pathology. The most common presenting symptom is a visible or palpable mass or an ulcerated nodule. MFH typically exhibits a broad range of diversity in its histopathological appearances and has been classified into five subtypes: storiform-pleomorphic, giant cell, inflammatory, myxoid and angiomatoid types. The tumor subtype in this patient was storiformpleomorphic, which accounts for up to $70 \%$ of all 
the reported cases ... Surgery in the form of wide excision is the primary modality of management of $\mathrm{MFH}^{(3)}$. Adjuvant radiotherapy and chemotherapy have been used either alone or in various combinations in an attempt to improve the survival outcomes. However no firm conclusions can be drawn with regard to their effectiveness ${ }^{(4)}$. Chemo radiotherapy has been more commonly used in patients with large unresectable tumors and in the setting of metastatic disease. The tumor cells in MFH have a tendency to grow along fascial planes making them more prone for local recurrence. Involvement of the skeletal muscle increases the chances of local recurrences from $27 \%$ to about $43 \%$. Metastatic disease has been reported in $0-43 \%$ of the pediatric $\mathrm{MFH}$ and 5$41 \%$ of adult $\mathrm{MFH}$, the most common site of metastasis being lung (90\%), followed by lymph nodes, $(35 \%)$ bones $(8 \%)$ and liver $(1 \%)^{(4)}$. The adverse prognostic factors include high histological grade, tumor size of $>5 \mathrm{~cm}$ and deep seated tumors

\section{References}

1. Krishnamurthy/ncbi.nlm.nih.gov/pmc/artic les/PMC4802572

2. Tsai EC, Santorenos S, Rutka J. Tumors of the skull base in children: Review of tumor types and management strategies. Neurosurg Focus. 2002;12:1-13.[PubMed]

3. Kubo T, Shimose S, Matsuo T, Arihiro K, Ochi M. Scalp metastasis from malignant fibrous histiocytoma of bone. J Am Acad Dermatol. 2008;59:S88-91. [PubMed]

4. Daw NC, Billups CA, Pappo AS, Jenkins JJ, Mahmoud $\mathrm{HH}$, Krasin $\mathrm{MJ}$, et al. Malignant fibrous histiocytoma and other fibrohistiocytic tumors in pediatric patients: The St. Jude Children's Research Hospital experience. Cancer. 2003; 97: 2839-47. [PubMed]
5. Belal A, Kandil A, Allam A, Khafaga Y, El-Husseiny G, El-Enbaby A, et al. Malignant fibrous histiocytoma: A retrospective study of 109 cases. Am J Clin Oncol. 2002;25:16-22. [PubMed]. 